\title{
Avaliação de gases poluentes oriundos da queima de argila com adição de escória de aciaria
}

\section{(Evaluation of pollutant gases resulting from firing clay with steel slag addition)}

\author{
V. P. Souza ${ }^{1}$, R. Toledo ${ }^{1}$, C. M. F.Vieira ${ }^{2}$, S. C. Intorne ${ }^{2}$, H. Vargas ${ }^{1}$, R. T. Faria Jr. ${ }^{1}$ \\ ${ }^{1}$ Laboratório de Ciências Físicas - LCFIS, ${ }^{2}$ Laboratório de Materiais Avançados - LAMAV \\ Universidade Estadual do Norte Fluminense Darcy Ribeiro - UENF \\ Av. Alberto Lamego, 2000, Pq. Califórnia, Campos dos Goytacazes, RJ 28013-600
}

\begin{abstract}
Resumo
Nos dias atuais a conscientização sobre a preservação ambiental tem destaque no setor industrial. A indústria cerâmica busca como alternativa de preservação e economia a agregação de diversos resíduos industriais. No entanto, há a preocupação com a emissão de gases poluentes na queima desses novos materiais. Este trabalho teve o objetivo de analisar as emissões gasosas liberadas durante a queima da mistura da argila do município de Campos dos Goytacazes, RJ, com diferentes concentrações de resíduo de escória de aciaria do processo LD (Linz Donawitz) de refino do aço. Os corpos-de-prova continham concentrações de escória com 0,5 e $10 \%$. Durante a queima foram detectados com destaque os gases $\mathrm{CO}_{2}$ e $\mathrm{CO}$ via técnica fototérmica. Com $10 \%$ de escória de aciaria houve um pico pronunciado de $\mathrm{CO}_{2}$ a $800{ }^{\circ} \mathrm{C}$, cujo perfil não apresenta na argila pura. Tal comportamento é possivelmente devido à desidroxilação da calcita.

Palavras-chave: gases, cerâmica vermelha, escória de aciaria, técnica fototérmica.
\end{abstract}

Abstract

Recently the awareness on the ambient preservation plays an important role in the industrial sector. The ceramic industry seeks, as an alternative of economy and preservation, the aggregation of diverse industrial residues. However, there is the concern with the pollutant gas emission in the clay firing process This work had the objective of analyzing gas emissions during firing the mixture of the clay from Campos dos Goytacazes, RJ, Brazil with different concentrations residue of steel slag in the LD (Linz Donawitz) process of steel refining. The samples contained slag concentrations with 0, 5 and 10\%. During firing, $\mathrm{CO}_{2}$ and $\mathrm{CO}$ gases had been detected using photothermal technique. There is a sharp $\mathrm{CO}_{2}$ peak at $800{ }^{\circ} \mathrm{C}$ in the firing of clay with $10 \%$ residue, probably due to calcite dehydroxilation, in relation to pure clay.

Keywords: gases, red ceramics, steel slag, photothermal technique.

\section{INTRODUÇÃO}

Em um mundo globalizado, o crescimento da atividade industrial impulsionou o desenvolvimento de novas técnicas para o processo produtivo e com isso a preocupação com a questão ambiental repercutiu de tal forma, que com o passar do tempo, mudou-se definitivamente a visão da Terra e das funções que executam as suas diversificadas populações. A preocupação com o impacto que as descobertas humanas ou produções provocam na Natureza vem aumentando no decorrer dos anos, de forma a transformar o modo de associar o ambiente e a sociedade como um sistema único, integrado.

A adequação ambiental de uma indústria deve-se ao conhecimento das leis e normas que controlam o setor além de investimentos em pesquisas e tecnologia. Futuramente, a sociedade exigirá que os produtos sejam ecologicamente corretos, sendo então, valorizados e deverão estar de acordo com as metas previstas nos novos regulamentos ambientais que comandarão os vários setores industriais. Com essa visão, pesquisadores e produtores estão preocupados em reduzir ou redirecionar os resíduos da fabricação de produtos diversos. Uma das aplicações é a utilização desses resíduos incorporados a argila, reduzindo, assim, o custo da produção e o impacto ambiental na região, preservando a matériaprima bruta usada, a argila, que ainda através de estudos trazer economia sem perder a qualidade. Contudo, surge um novo alerta, a necessidade de analisar os gases emitidos pelo processo de queima dessas novas misturas argilosas.

Os centros de pesquisa em cerâmica estão analisando vários tipos de resíduo incorporados à argila, tais como: resíduos da indústria de rochas ornamentais [1-3], resíduo do setor siderúrgico $[4,5]$, resíduo de boro [6], resíduo de curtume [7], resíduo da indústria de galvanização [8], lodos 
de estação de tratamento de águas [9, 10], entre outros. Em geral, esses trabalhos estão relacionados às mudanças estruturais e físicas que esses resíduos provocam no produto cerâmico, destacando a preocupação com a qualidade do produto final.

A indústria siderúrgica gera uma quantidade significativa e diversificada de resíduos sólidos. A escória de aciaria representa um volume aproximadamente de $80 \%$ do total de resíduos gerados. Uma alternativa viável econômica e ambientalmente, como solução para o descarte desse resíduo é a incorporação à massa argilosa, já que a composição química da massa argilosa pode tolerar a presença de outros tipos de materiais ainda que em quantidades relativamente alta [11].

O processamento de materiais cerâmicos que envolvem queima está associado à liberação de componentes gasosos, que não têm sido suficientemente investigados, apenas na última década tem-se aprofundado o conhecimento dos diversos aspectos ambientais que lhe são inerentes [12]. Em geral, a queima de massas argilosas pode liberar concentrações apreciáveis de certos componentes gasosos como: monóxido de carbono ( $\mathrm{CO}$ ), dióxido de carbono $\left(\mathrm{CO}_{2}\right)$, óxidos de nitrogênio $\left(\mathrm{NO}_{\mathrm{x}}\right)$, óxidos de enxofre $\left(\mathrm{SO}_{\mathrm{x}}\right)$, amônia $\left(\mathrm{NH}_{3}\right)$ e metano $\left(\mathrm{CH}_{4}\right)$, além da emissão de compostos orgânicos fluorados, que em fortes concentrações prejudicam o meio-ambiente, equipamentos, ferramentas e principalmente a saúde humana [12-13]. A análise gasosa, juntamente com os ensaios tecnológicos, é mais uma forma de se verificar se uma mistura é viável ou não, sob o ponto de vista ambiental [14].

$\mathrm{Na}$ próxima seção, serão comentados os materiais e métodos utilizados para analisar os gases emitidos na queima de corpos-de-prova de argila misturados com resíduos de aciaria, bem como a composição química e mineralógica. $\mathrm{Na}$ seção seguinte, os resultados serão apresentados e, por último, as conclusões.

\section{MATERIAIS E MÉTODOS}

Foram utilizados os seguintes materiais: massa argilosa normalmente empregada na fabricação de cerâmica vermelha no município de Campos dos Goytacazes-RJ; escória de aciaria proveniente da siderurgia nacional, que utiliza o processo LD de refino do aço que passou pelo processo de peneiramento em malha de 20 mesh e moagem, devido à granulometria grosseira, de $7860 \mu \mathrm{m}$ [11].

Os corpos-de-prova possuíram formato retangular com dimensões $114,5 \times 25,4 \times 10 \mathrm{~mm}^{3}$ com $8 \%$ de umidade e conformados por prensagem uniaxial a $20 \mathrm{MPa}$. Foram preparados com adição à massa de $0 \%$ em peso de resíduo (argila pura), 5\% e 10\% de escória de aciaria. A massa argilosa possui coloração amarelada devido ao elevado teor de compostos de ferro que é predominantemente composta de caulinita, quartzo, mica muscovita, gibsita, goetita e ilita [15]. Em seguida foram secos em estufa a $110^{\circ} \mathrm{C}$ até peso constante. A queima foi realizada em um forno tubular resistivo (Maitec modelo FT-1200BI), especial para a detecção de gases. As temperaturas selecionadas foram 150, $300,450,550,650,800,950,1050$ e $1100{ }^{\circ} \mathrm{C}$. O ciclo de queima do forno foi de $2{ }^{\circ} \mathrm{C} / \mathrm{min}$ até $500{ }^{\circ} \mathrm{C}$ e $4{ }^{\circ} \mathrm{C} / \mathrm{min}$ até $1100^{\circ} \mathrm{C}$ com tempo de permanência, em cada patamar, de 20 min sob o fluxo de $3 \mathrm{~mL} / \mathrm{min}$. O resfriamento foi realizado desligando-se o forno e mantendo os corpos-de-prova em seu interior até temperatura ambiente.

A composição química da escória de aciaria foi determinada por espectroscopia de fluorescência de raios $\mathrm{X}$ por dispersão de energia em equipamento EDX Shimadzu. Para a determinação de fases cristalinas, o resíduo foi submetido a análise de difração de raios X (DRX) em difratômetro Seifert modelo URD65, operando com radiação $\mathrm{Cu}-\mathrm{k}_{\alpha}$ e $2 \theta$ variando de $5^{\circ}$ a $70^{\circ}$.

Como metodologia complementar foi utilizada a técnica fototérmica [16] para a medida das concentrações dos gases. O sistema de quantificação e detecção de gases consistiu de um analisador de gases na faixa do infravermelho (URAS14ABB) conectado ao forno.

A Fig. 1 apresenta o sistema de funcionamento do URAS-14, onde ocorre a seleção dos comprimentos de onda das espécies sob investigação de uma forma simultânea. Assim, de uma mesma amostra de gases, quantificaram-se os compostos gasosos previamente selecionados, sendo eles $\mathrm{CO}, \mathrm{CO}_{2}, \mathrm{CH}_{4}, \mathrm{SO}_{2}, \mathrm{NH}_{3}, \mathrm{NO}$ e $\mathrm{N}_{2} \mathrm{O}$.

$\mathrm{O}$ analisador de gases URAS-14 consiste de um emissor de luz, no qual as emissões alcançam a célula da amostra, após a passagem por um dispositivo (chopper) que faz com que a luz infravermelha passe a ser modulada, além de conter uma célula dividida em 2 compartimentos: uma célula de medida, pela qual a amostra analisada flui e uma célula de referência preenchida com gás inerte, o nitrogênio. $\mathrm{O}$ detector do analisador consiste de duas câmaras seladas separadas por um diafragma ou membrana capacitiva. Ambas as câmaras são preenchidas com o gás puro (certificado) da espécie química sob investigação. Os feixes de luz que saem da amostra e

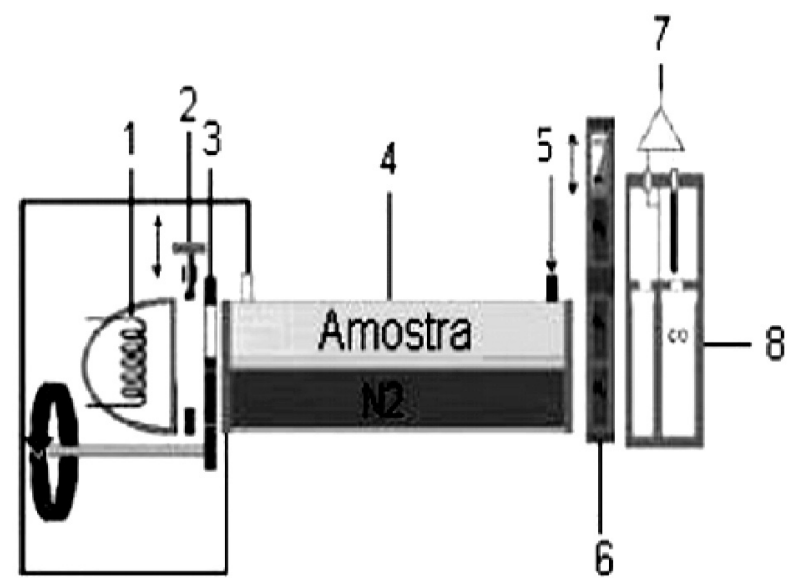

Figura 1: Sistema de funcionamento do URAS-14. 1: fonte térmica (infravermelho); 2: janela óptica; 3: obturador eletromecânico; 4: câmara de gases $\left(\mathrm{N}_{2}\right.$ e amostra gasosa); 5: entrada do gás de amostra; 6: janela óptica; 7: amplificador; 8: câmara de análise. [Figure 1: Schematic design of the URAS-14 system operation.] 
da célula de referência alcançam independentemente as duas câmaras do detector, provocando uma pressão diferencial que é proporcional à absorção de luz pela amostra. A diferença de pressão é convertida pelo diafragma capacitivo em um sinal elétrico, que está conectado 'a entrada de um amplificador comparador que possui em sua entrada o sinal de referência. A diferença entre os dois sinais é a medida de concentração do gás sob investigação [17].

\section{RESULTADOS E DISCUSSÃO}

A Fig. 2 ilustra o difratograma de raios $\mathrm{X}$ da escória de aciaria, onde foram identificados picos de difração associados a fases cristalinas predominantemente formadas de $\mathrm{Ca}$ e $\mathrm{Fe}$.

As fases ricas em $\mathrm{Ca}$ são a calcita $\left(\mathrm{CaCO}_{3}\right)$ e silicatos de cálcio, larnita $\left(\mathrm{Ca}_{2} \mathrm{SiO}_{4}\right)$ e wolastonita $\left(\mathrm{CaSiO}_{3}\right)$. Os compostos de ferro identificados estão presentes na forma de magnetita $\left(\mathrm{FeFe}_{3} \mathrm{O}_{4}\right)$ e wustita $(\mathrm{FeO})$, além da ocorrência de fosfato de ferro $\left(\mathrm{Fe}_{4}\left(\mathrm{P}_{2} \mathrm{O}_{7}\right)_{3}\right)$. Foi ainda identificada a presença de óxido de titânio $\left(\mathrm{TiO}_{2}\right)$. Picos de difração de baixa intensidade do $\mathrm{MgO}$ também foram identificados, indicando estar este óxido na forma livre.

A escória é predominantemente formada por compostos de $\mathrm{Ca}, \mathrm{Fe}, \mathrm{Mg}$ e Si, como é apresentado na Tabela I (\% em peso).

Vale ressaltar que a escória de aciaria pode apresentar uma composição mineralógica bastante complexa, em função das reações que podem ocorrer entre os diversos

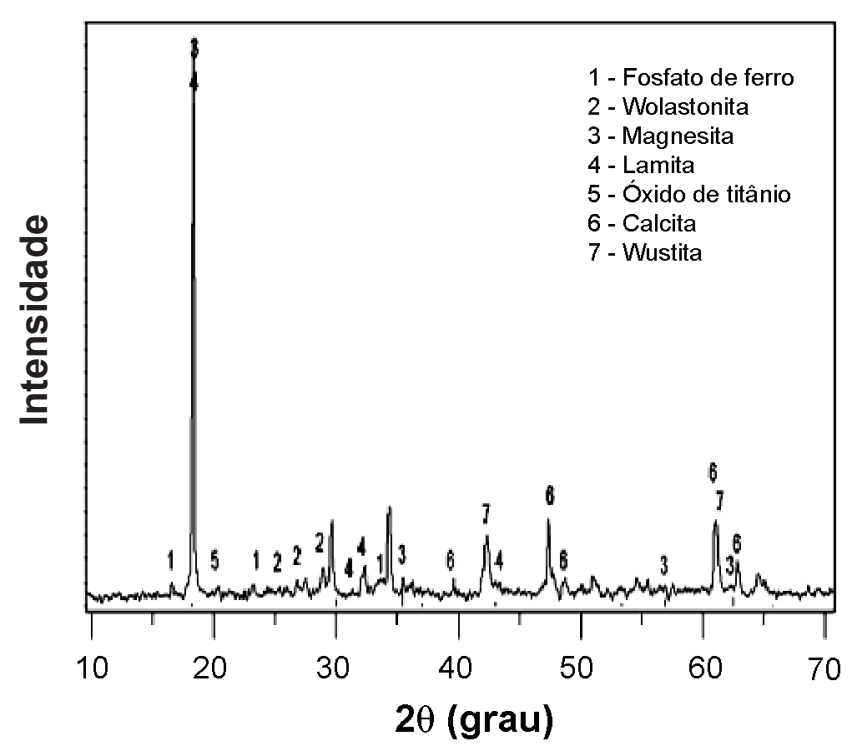

Figura 2: DRX da escória de aciaria.

[Figure 2: X-ray diffraction pattern of the steel slag.]

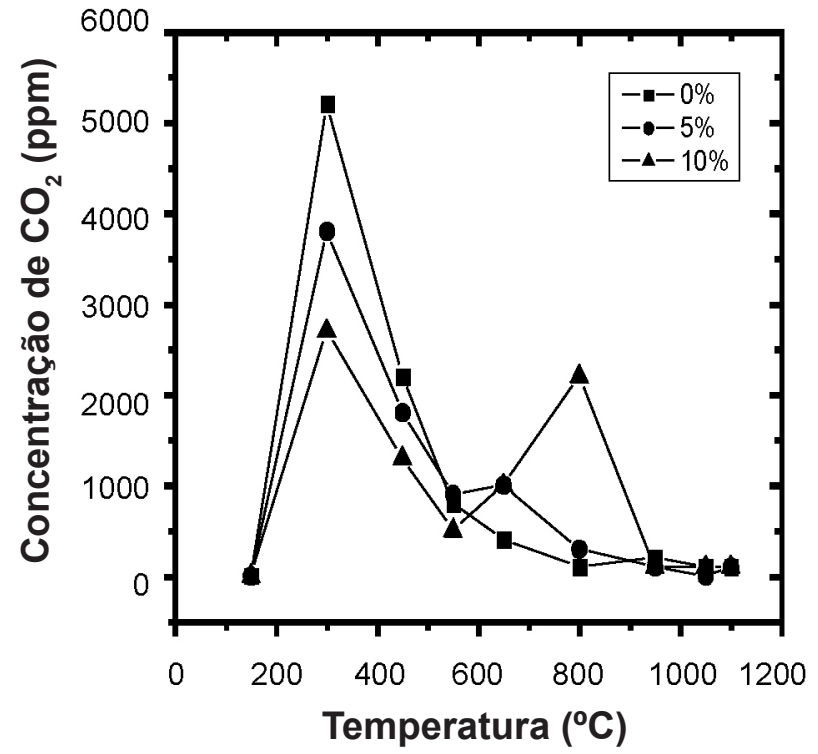

Figura 3: Liberação de $\mathrm{CO}_{2}$ em relação a temperatura.

[Figure 3: $\mathrm{CO}_{2}$ profile as a function of the firing temperature.]

constituintes utilizados na obtenção do aço e das próprias características do processamento [11].

$\mathrm{O} \mathrm{CO}_{2}$ e o $\mathrm{CO}$ foram as espécies gasosas que apresentaram valores mais significativos, para a adição de escória de aciaria à massa argilosa, como mostram as Figs. 3 e 4. Estes estão associados pela relação de combustão ocorrida, durante a queima dos corpos-de-prova, através das condições atmosféricas do forno.

Comparando as diferentes porcentagens de resíduos adicionados à massa argilosa, observou-se a redução das concentrações dos gases $\mathrm{CO}_{2}$ e CO, até a faixa de temperatura dos $550{ }^{\circ} \mathrm{C}$, à proporção que se aumentava a porcentagem de resíduo. No perfil de $\mathrm{CO}_{2}$, no corpo-de-prova com $10 \%$ de escória, no pico referente a $800{ }^{\circ} \mathrm{C}$, houve um aumento da concentração. Uma provável origem é a quebra de carbonatos presentes na escória que se desequilibram estruturalmente nesta faixa de temperatura. $\mathrm{O}$ carbonato mais abundante detectado pelo difratograma (Fig. 2) foi a calcita, que se decompõe de forma completa entre $675^{\circ} \mathrm{C}$ e $950{ }^{\circ} \mathrm{C}$ [11]. A emissão de $\mathrm{CO}_{2}$ em temperaturas superiores a $850^{\circ} \mathrm{C}$, é provável que seja decorrente da decomposição final da calcita $\left(\mathrm{CaCO}_{3}{ }^{\circledR} \mathrm{CaO}+\mathrm{CO}_{2}\right)$ e de moléculas residuais aprisionadas no interior do corpo-de-prova [11]. Essas liberações são favorecidas pela abertura dos poros provocada pela desidroxilação final dos minerais micáceos que deve ocorrer aproximadamente até $950^{\circ} \mathrm{C}$.

Tabela I - Composição química da escória (peso\%).

[Tabel I - Chemical composition of the steel slag]

\begin{tabular}{ccccccccccc}
\hline $\mathrm{CaO}$ & $\mathrm{Fe}_{\text {TоTAL }}$ & $\mathrm{SiO}_{2}$ & $\mathrm{MnO}$ & $\mathrm{SO}_{3}$ & $\mathrm{TiO}_{2}$ & $\mathrm{SrO}$ & $\mathrm{Al}_{2} \mathrm{O}_{3}$ & $\mathrm{P}_{2} \mathrm{O}_{5}$ & $\mathrm{MgO}$ & $\mathrm{PF}$ \\
\hline 45,10 & 23,62 & 10,29 & 5,40 & 0,54 & 0,34 & 0,18 & 2,90 & 1,81 & 10,33 & 12,96 \\
\hline
\end{tabular}




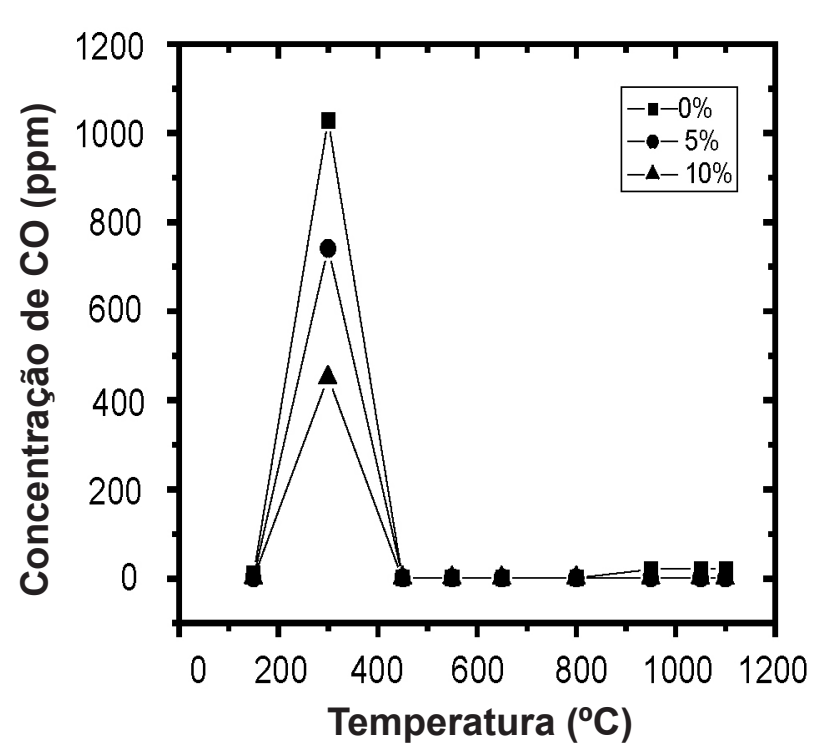

Figura 4: Liberação de $\mathrm{CO}$ em relação a temperatura.

[Figure 4: CO profile as a function of the firing temperature.]

\section{CONCLUSÕES}

É importante ressaltar que este trabalho não buscou determinar o valor real das concentrações gasosas emitidas em indústrias cerâmicas, pois foi realizado em laboratório, simplesmente simulando o processo de queima industrial. O objetivo foi determinar o perfil dos gases emitidos, considerando os diversos teores de resíduos incorporados à massa e, assim, analisar o comportamento cinético do processo de queima no interior do forno.

Diante dos gases sob investigação, foram detectados o $\mathrm{CO}_{2}$ e o $\mathrm{CO}$; visto que o $\mathrm{CO}$ é conseqüência das condições atmosféricas do forno, ou seja, se estiver rico em oxigênio a concentração de $\mathrm{CO}_{2}$ será bem maior que a do CO. Este perfil só é válido qualitativamente.

Pode-se afirmar que à proporção que se incorpora $\mathrm{o}$ resíduo, diminui-se a emissão dos gases poluentes na faixa de 200 a $500{ }^{\circ} \mathrm{C}$. Por outro lado, entre $600{ }^{\circ} \mathrm{C}$ e $950{ }^{\circ} \mathrm{C}$, em relação à argila pura da região Norte Fluminense, normalmente há uma baixa emissão de gases, há um pico de intensidade alta de $\mathrm{CO}_{2}$, acarretando, no caso do corpode-prova com $10 \%$ de incorporação de escória, um aumento considerável da emissão de $\mathrm{CO}_{2}$, o que torna preocupante em termos de impacto ambiental. Assim, indica-se, pelo ponto de vista gasoso, que a reciclagem da escória de aciaria devese limitar a uma queima de até $550^{\circ} \mathrm{C}$, no caso da adição de altas concentrações. Assim, sugere-se que a concentração de resíduos de aciaria a ser incorporada à massa argilosa deve ser inferior a $10 \%$, beneficiando, então, o meio ambiente bem como as indústrias de cerâmica e siderúrgica.

\section{AGRADECIMENTOS}

À FAPERJ e ao CNPq pelo suporte financeiro.

\section{REFERÊNCIAS}

[1] H. F.Mothé Filho, H. Polianov, E. V. Barroso, C. G. Mothé, Thermochim. Acta 392-393 (2002) 47-50.

[2] R. R. Menezes, H. S. Ferreira, G.A. Neves, H.C. Ferreira, Cerâmica 48, 306 (2002) 92-101.

[3] A. M. Segadães, M. A. Carvalho, W. Acchar, Appl. Clay Sci. 30 (2005) 42-52.

[4] E. A. Domingues, R. Ullmann, Appl. Clay Sci. 11 (1996) 237-5249.

[5] G. E. Oliveira, J. N. F. Holanda, Waste Manag. Res. 22 (2004) 358-363.

[6] T. Uslu, A. I. Arol, Waste Manag. 24 (2002) 47-50.

[7] T. Basegio, F. Berutti, A. Bernardes, C. P. Bergman, J. Eur. Ceram. Soc. 22, 13 (2002) 2251-2259.

[8] J. M. Magalhães, J. E. Silva, F. P. Castro, J. A. Labrincha, J. Hazardous Mater. 106, 2-3 (2004) 139-147.

[9] E. M. S. Oliveira, V. G. Sampaio, J. N. F. Holanda, Ind. Ceram. 26 (2006) 23-28.

[10] S. R. Teixeira, S. A. Souza, N. R. Souza, P. Aléssio, G. T. A. Santos, Cerâmica 52, 323 (2006) 215-220.

[11] E. L. dos Santos, S. C. Itorne, D. P. Dias, C. M. F. Vieira, S. N. Monteiro, $49^{\circ}$ Cong. Bras. Cerâmica, S. Pedro, SP (2005).

[12] M. Almeida, P. Frade, H. Campante. Cerâmica Ind. 6 (2001) 7-13

[13] D. J. Morgan, Appl. Clay Sci. 8 (1993) 81-89.

[14] J. Alexandre, F. Saboya, B. C. Marques, M. L. P. Ribeiro, C. Salles, M. G. Silva, M. Sthel, S. L. T. Auler, H. Vargas, The Analyst 124 (1999) 1209.

[15] E. M. S. Oliveira, Tese de Doutorado, Universidade Estadual do Norte Fluminense, Campos dos Goytacazes, RJ (2004).

[16] R. T. Faria Jr., M. P. P. Castro, J. Alexandre, R. Toledo, L. O.Carneiro, W. S. Ribeiro, M. S. Sthel, D. U. Schramm, H. Vargas, J. Phys. IV 125 (2005) 837-840.

[17] R. Toledo, D. R. Santos, R. T. Faria Jr., J. G. Carrió, L. T. Auler, H. Vargas, Appl. Clay Sci. 27 (2004) 151-157

(Rec. 06/03/2008, Ac. 16/05/2008) 